\title{
Temporal Variations of Urban Heat Island Intensity in Three Major Cities, Thailand
}

\author{
Yenrutai Jongtanom \\ Environmental Science (Interdisciplinary Program) \\ Graduate School, Chulalongkorn University \\ Phyathai Road, Pathumwan, Bangkok 10330, Thailand \\ E-mail: yenrutai@hotmail.com
}

Charnwit Kositanont (Corresponding author)

Faculty of Science, Chulalongkorn University

Phyathai Road, Pathumwan, Bangkok 10330, Thailand

E-mail: charnwit@sc.chula.ac.th

Surat Baulert

College of Environment, Kasetsart University

Ngam Wong Wan Road, Chatuchak, Bangkok 10900, Thailand

E-mail: surat.b@ku.ac.th

Received: June 28, 2011

Accepted: August 7, 2011

doi:10.5539/mas.v5n5p105

This work was funded by The 90 ${ }^{\text {th }}$ Anniversary of Chulalongkorn University Fund (2009) (Ratchadaphiseksomphot Endowment Fund)

\begin{abstract}
The mean maximum urban heat island (UHI) intensity in three major cities in Thailand was investigated by using data measured at two meteorological observatories (an urban site and rural site) in each study area for the period 2004 to 2008. Thermal contrasts between the urban and rural sites were positive which indicated that most of the time the air temperatures at the urban sites were higher than the air temperatures at the rural sites. The strongest mean maximum UHI intensity occurred in the nighttime and in the early morning, while the weakest mean maximum UHI intensity was reached during the daytime. The results indicated that UHI events occurred more frequently in the nighttime than in the daytime. Seasonal analyses showed the mean maximum UHI intensity was weakest in the rainy season (May-October) and was strongest in the dry season (November-April).
\end{abstract}

Keywords: Mean maximum urban heat island (UHI) intensity, Major cities, Thailand

\section{Introduction}

The urban heat island (UHI) phenomenon is considered to be one of the major problems for human population in the $21^{\text {th }}$ century as a result of urbanization and industrialization (Zhou et al., 2004; Rizwan et al., 2008; Zhang et al., 2009). This phenomena is referred to surface air temperature in an urban area is higher than in the surrounding rural area (Magee et al., 1999; Kim and Baik, 2002, 2005). The large amount of heat generated from urban structure, as they absorb and reradiate solar radiation, and from anthropogenic heat sources are the main causes of UHI (Rizwan et al., 2008; Zhang et al., 2009). Urban areas in Thailand have been developed as the dominant centers for economic activities, industrialization, social services, telecommunications, and public welfare infrastructure. Change in populations and change in land use caused urban areas in Thailand are facing a high risk of UHI effect. Many previous studies have shown that the intrinsic nature of the city and external factors influenced the UHI effect, including size of the city, building intensity, land use, topography, meteorological conditions, and time of day (Oke, 1982; Magee et al., 1999; Kim and Baik, 2005; Zhang et al., 2009). The UHI has been investigated in many cities to establish the UHI intensity. This is defined as the average spatial temperature 
difference between an urban area and the surrounding rural area (Magee et al., 1999; Kim and Baik, 2005; Zhang et al., 2009). The UHI intensity which determined by comparing the mean and maximum temperature between an urban and a rural area are referred to as the mean and maximum UHI intensity respectively (Rizwan et al., 2008). The comparison time period used to be a month, a season, or a year, or in some cases using few selected days (Velazquez-Lozada et al., 2006). The mean maximum intensity stands for the highest daily warming of an urban area under most favorable weather conditions, such as few or no clouds and low wind (Wienert and Kuttler, 2005). In previous studies, the UHI effect has mainly been analyzed using two methods. The most popular method has been satellite remote sensing. This method can provide a qualitative measure of the distribution of UHI at a given moment, but it cannot do the same for the UHI intensity (Liu et al., 2006). The second method used meteorological data to analyze the UHI effect by comparing the thermal data series of an urban area with those corresponding to a nearby rural area (Alonso et al., 2003; Arnfield, 2003). Most previous studied focused on UHI effect in a single megalopolis, for example, Seoul (Kim and Baik, 2002, 2005), Beijing (Liu et al., 2006), New York (Gaffin et al., 2008), Shanghai (Zhang et al., 2009). However there have been few studies of UHI in Thailand. This present study investigated the mean maximum UHI intensity in three major cities in Thailand by using the maximum temperature from the period 2004 to 2008 recorded at selected urban and rural weather stations. It focused on: (1) diurnal variations in UHI intensity (2) seasonal variations in UHI intensity.

\section{Study sites description and Data processing}

\section{1 study sites}

Bangkok, Chiang Mai and Songkhla were selected to be the study sites. They are the major cities in Thailand which have been developed as the cultural, intellectual center of the country, as well as major commercial metropolis. The criteria for the selection of the local weather stations in the study sites were each urban station had to lie in an area that was representative of the typical characteristics of the city, while each rural station had to lie outside the area of urban influence (Alonso et al., 2003). The first site was Bangkok, which is both the capital of Thailand, and the largest urban area in the country. Bangkok is about $2 \mathrm{~m}$. above sea level, and has a tropical wet and dry climate with three seasons, namely summer, the rainy season and winter. The urban weather station used in the study was Chaloemprakiet Meteorological Station which was located in the Khlong Toei district. The rural weather station was Bang Na Meteorological Station, which was located approximately $30 \mathrm{~km}$. from downtown Bangkok in the Bang Na district. The second site was Chiang Mai, which is the largest city in northern of Thailand. It is located $700 \mathrm{~km}$. to the north of Bangkok among high mountains, and is about $310 \mathrm{~m}$. above sea level. Like Bangkok, Chiang Mai has a tropical climate with three seasons, namely summer, the rainy season, and winter. The urban weather station selected for this study was Chiang Mai Meteorological Station which was located in the Mueang district. The rural weather station was Mae Jo Meteorological Station which was located approximately $25 \mathrm{~km}$ from Chiang Mai in the Sansai district. The third site was Songkhla which is one of the southern cities of Thailand. It is about $10 \mathrm{~m}$. above sea level, and has two seasons, the rainy season and summer. The urban weather station was Had Yai Meteorological Station which was located in the Had Yai district. The rural weather station was Sadao Meteorological Station which was located approximately $60 \mathrm{~km}$ from Had Yai in the Sadao district. The locations and descriptions of the stations are shown in Table 1.

\subsection{Data processing}

2.2.1 The data of maximum air temperature in study sites from the period 2004 to 2008 was obtained from automatic weather stations operated by the Thai Meteorological Department (TMD).

2.2.2 The data of maximum air temperature from local automatic weather stations was analyzed for studying the $\mathrm{UHI}$ intensity which was defined as the temperature difference between an urban area and its surrounding rural area. The UHI intensity was calculated by the equation below; where, $\Delta T$ represented the UHI intensity, $T_{u}$ was the air temperature in an urban area, and $T_{r}$ was the air temperature in a rural area.

$$
\Delta T_{u-r}=T_{u}-T_{r}
$$

2.2.3 In order to calculate hourly values; the UHI intensity was averaged for each individual hour of the diurnal cycle of the study years to calculate mean hourly values.

2.2.4 In order to calculate monthly values; the UHI intensity was averaged for each individual month of the study years to calculate mean monthly values.

2.2.5 The highest mean UHI intensity was taken as the mean maximum UHI intensity. 


\section{Results and Discussions}

\subsection{Diurnal variations in UHI intensity}

The diurnal variations in UHI intensity were shown in Figure 1. The mean maximum UHI intensity at all sites were positive which indicated that the air temperatures at urban sites were higher than at rural sites most of the time. The greatest mean maximum UHI intensity occurred at 04:00 LST in Bangkok $\left(2.24^{\circ} \mathrm{C}\right)$, at 07:00 LST in Chiang Mai $\left(2.73^{\circ} \mathrm{C}\right)$, and at 22:00 LST in Songkhla $\left(2.42^{\circ} \mathrm{C}\right)$. The weakest mean maximum UHI intensity occurred at 10:00 LST in Bangkok $\left(0.54^{\circ} \mathrm{C}\right)$, at 13:00 LST in Chiang Mai $\left(0.77^{\circ} \mathrm{C}\right)$ and Songkhla $\left(0.53^{\circ} \mathrm{C}\right)$. The results indicated that the largest mean maximum UHI intensity occurred during the nighttime and the early morning, while the weakest mean maximum UHI intensity occurred during the daytime. The results of this study were similar to previous studies on other cities such as Seoul (Kim and Baik, 2005), Singapore (Winston and Matthias, 2006), Beijing (Liu et al., 2006). The criteria for UHI event was thermal contrasts between an urban and a rural area more than $1^{\circ} \mathrm{C}$ which was maintained over several hours (Jauregui, 1997; Kim and Baik, 2002). The results from this study indicated that UHI events occurred more frequently at nighttime than in the daytime (Table 2.). These results can be explained by differences in cooling rates between urban and rural areas at night (Kim and Baik, 2002; Zhang et al., 2009). The cooling rates are influenced by surface geometry and surface thermal properties (Oke et al., 1991). During the day, urban surfaces trap more incoming solar radiation than surfaces in rural areas. Then they re-radiate it less at night than surfaces in rural areas. The ability of heat release by long-wave radiation in urban areas is low due to decreased sky view which results in heat storage in building structures (Rizwan et al., 2008). While the open spaces of the rural areas enhances radiative cooling because the areas cannot confine air which has been heated during the day (Liu et al., 2006). In addition, the urban areas release heat at night from human activities, light, traffic, etc. which play a significant role in increase the UHI events at nighttime.

\subsection{Seasonal variations in UHI intensity}

Air temperature differences between urban and rural stations also showed seasonal variations. Figure 2 shows the mean monthly maximum UHI intensity in the study areas. The monthly mean maximum UHI intensity in Bangkok was the greatest in February $\left(1.06^{\circ} \mathrm{C}\right)$, while the weakest mean maximum UHI intensity was found in July $\left(0.18^{\circ} \mathrm{C}\right)$. The monthly mean maximum UHI intensity in Chiang Mai and Songkhla were the greatest in April $\left(2.73^{\circ} \mathrm{C}\right.$ and $\left.2.70^{\circ} \mathrm{C}\right)$, while the weakest mean maximum UHI intensity in Chiang Mai was found in August $\left(0.9^{\circ} \mathrm{C}\right)$ and in Songkhla was found in July $\left(0.24^{\circ} \mathrm{C}\right)$. These results indicated that the largest mean maximum UHI intensity at study sites which have three seasons occurred in the dry season (November-April), and declined to a minimum during the rainy season (May-October). The largest mean maximum UHI intensity in Songkhla which has two seasons was found in summer (February-June), while the weakest mean maximum UHI intensity occurred in the rainy season (July-January). The key factor for the seasonal variations in UHI intensity is probably the differences in weather conditions (Montavez et al., 2000; Unger et al., 2001; kim and Baik, 2002; Zhang et al., 2009). Many previous studies have indicated that the UHI intensity was related to local meteorological conditions. Kim and Baik (2002) reported that a decrease in maximum UHI intensity could be visible with wind speed greater than 0.8 $\mathrm{m} / \mathrm{s}$ while with the critical wind speed of $7.0 \mathrm{~m} / \mathrm{s}$ maximum UHI intensity of $0.3^{\circ} \mathrm{C}$ or less could vanish. Liu et al. (2006) reported that in summer, when relative humidity was high, the UHI intensity was low. Chow and Roth (2006) reported that the seasonal variability in the UHI intensity related to the variability of moisture content, which was largely influenced by the seasonal variation of precipitation. Zhang et al. (2009) reported that the wind speed and cloudiness had the smallest values in autumn, so at that time the UHI intensity was the strongest and the highest wind speed and cloudiness caused the UHI intensity was the weakest in summer.

\section{Conclusion}

This study investigated the mean maximum urban heat island (UHI) intensity in three major cities in Thailand. The methodology was using data at two meteorological stations (an urban station and a rural station) in each study site from the period 2004 - 2008 to calculate the UHI intensity. The mean maximum UHI intensity was found to be the strongest in the nighttime and the early morning, while the mean maximum UHI intensity was found to be the weakest in the daytime. The UHI events more frequently occurred in the nighttime than in the daytime. The results showed seasonal variations in UHI intensity. The mean maximum intensity was the weakest in the rainy season and was the strongest in dry season. The present study has shown temporal variations of UHI intensity. However, the local weather conditions and the local characteristics of urban areas (e.g. building density, kind of building material) seem to be the dominating factors in the formation of UHI. Future research should to investigate the relationship between the UHI intensity and the local weather conditions. 


\section{References}

Alonso, M.S., Labajo J.L., \& Fidalgo, M.R. (2003). Characteristics of the urban heat island in the city of Salamanca, Spain. Atmósfera. 16, 137-148.

Arnfield, A.J. (2003). Two decades of urban climate research: a review of turbulence, exchanges of energy and water, and the urban heat island. International Journal of climatology. 23, 1-26. doi:10.1002/joc.859, http://dx.doi.org/10.1002/joc.859

Chow, W.T.L., \& Roth M. (2006). Temporal Dynamics of the urban heat island of Singapore. . International Journal of Climatology. 26, 2243-2260. doi:10.1002/joc.1364, http://dx.doi.org/10.1002/joc.1364

Gaffin, S.R., Rosenzweig, C., Khanbilvardi, R., Parshall, L., et al. (2008) Variation in New York city's urban heat island strength over time and space. Theoretical and Applied Climatology. 94(1-2), 1-11. doi:10.1007/s00704-007-0368-3, http://dx.doi.org/10.1007/s00704-007-0368-3

Jauregui, E. (1997). Heat island development in Mexico City. Atmospheric Environment. 3(22), 3821-3831. doi:10.1016/S1352-2310(97)00136-2, http://dx.doi.org/10.1016/S1352-2310(97)00136-2

Kim, Y.H., \& Baik, J.J. (2002). Maximum urban heat island intensity in Seoul. Journal of Applied Meteorology. 41, 651-659. doi:10.1175/1520-0450(2002)041<0651:MUHIII >2.0.CO;2, http://dx.doi.org/10.1175/1520-0450(2002)041<0651:MUHIII >2.0.CO;2

Kim, Y.H., \& Baik, J.J. (2005). Spatial and temporal structure of the urban heat island in Seoul. Journal of Applied Meteorology. 44, 591-605. doi:10.1175/JAM2226.1, http://dx.doi.org/10.1175/JAM2226.1

Liu, W., Ji, C., Zhong, J., Jiang, X., \& Zheng, Z. (2006). Temporal characteristics of the Beijing urban heat island. Theoretical and Applied Climatology. 87(1-4), 213-221. doi:10.1007/s00704-005-0192-6, http://dx.doi.org/10.1007/s00704-005-0192-6

Magee, N., Curtis, J., \& Wendler, G. (1999). The urban heat island effect at Fairbanks, Alaska. Theoretical and Applied Climatology. 64(1-2), 39-47. doi:10.1007/s007040050109, http://dx.doi.org/10.1007/s007040050109

Montavez, J.P., Rodrigues, A., \& Jimenez, J.I. (2000). A study of the urban heat island of Granada. International Journal of Climatology. 20, 899-911. doi:10.1002/1097-0088(20000630)20:8<899::AID-JOC433>3.0.CO;2-I, http://dx.doi.org/10.1002/1097-0088(20000630)20:8<899::AID-JOC433>3.0.CO;2-I

Oke, T.R.( 1982). The energetic basis of the urban heat island. Quarterly Journal of the Royal Meteorological Society. 108, 1-24.

Oke, T.R., Johnson, G.T., Steyn, D.G., \& Watson, I.D. (1991). Simulation of surface urban heat island under 'ideal' conditions at night. Part 2: diagnosis of causation. Boundary-Layer Meteorology. 56, 339-358. doi:10.1007/BF00119211, http://dx.doi.org/10.1007/BF00119211

Rizwan, A.M., Leung, D.Y.C., \& Liu, C. (2008). A review on the generation, determination and mitigation of urban heat island. Journal of Environment Science. 20(1), 120-128. doi:10.1016/S1001-0742(08)60019-4, http://dx.doi.org/10.1016/S1001-0742(08)60019-4

Unger, J., Sumeghy, Z., \& Zoboki, J. (2001). Temperature cross-section features in an urban area. Atmospheric Research. 58, 117-127. doi:10.1016/S0169-8095(01)00087-4, http://dx.doi.org/10.1016/S0169-8095(01)00087-4

Velazquez-Lozada, A., Gonzalez, J.E., \& Winter, A. (2006). Urban heat island effect analysis for San Juan, Puerto Rico. Atmospheric Environment. 40, 1731-1741. doi:10.1016/j.atmosenv.2005.09.074, http://dx.doi.org/10.1016/j.atmosenv.2005.09.074

Wienert, U., \& Kuttler, W. (2005).The dependence of the urban heat island intensity on latitude-A statistical approach. Meteorologische Zeitschrift. 14, 677-686. doi:10.1127/0941-2948/2005/0069, http://dx.doi.org/10.1127/0941-2948/2005/0069

Winston, T.L., \& Matthias, R. (2006). Temporal dynamics of the urban heat island of Singapore. International Journal of Climatology. 26:2243-2260. doi:10.1002/joc.1364, http://dx.doi.org/10.1002/joc.1364

Zhang, K., Wang R., Shan, C., \& Da, L., (2009). Temporal and spatial characteristics of the urban heat island during rapid urbanization in Shanghai, China. Environmental Monitoring and Assessment. 169(1-4), 101-112. doi:10.1007/s10661-009-1154-8, http://dx.doi.org/10.1007/s10661-009-1154-8

Zhou, L.M., Dickinson, R.E., Tian, Y.H., Fang, J.Y., Li, Q.X., Kaufmann, R.K., et al. (2004). Evidence for a significant urbanization effect on climate in China. Proceedings of the National Academy of Sciences of the 
United States of America. 101(26), 9540-9544. doi:10.1073/pnas.0400357101, http://dx.doi.org/10.1073/pnas.0400357101

Table 1. Location and description of urban and rural weather stations

\begin{tabular}{|c|c|c|c|}
\hline Station description & Urban station & Rural station & Notes \\
\hline Bangkok & Chaloemprakiet Station & Bang Na Station & Instrument height is $10 \mathrm{~m}$. \\
\hline Altitude (m) & 2 & 3 & all stations \\
\hline Longitude & $100.30^{\circ} \mathrm{E}$ & $100.36^{\circ} \mathrm{E}$ & \\
\hline Latitude & $13.44^{\circ} \mathrm{N}$ & $13.4{ }^{\circ} \mathrm{N}$ & \\
\hline Chiang Mai & Chiang Mai Station & Mae Jo Station & \\
\hline Altitude (m) & 312 & 317 & \\
\hline Longitude & $98.59^{\circ} \mathrm{E}$ & $99.0^{\circ} \mathrm{E}$ & \\
\hline Latitude & $18.47^{\circ} \mathrm{N}$ & $18.55^{\circ} \mathrm{N}$ & \\
\hline Songkhla & Had Yai Station & Sadao Station & \\
\hline Altitude (m) & 4 & 24 & \\
\hline Longitude & $100.30^{\circ} \mathrm{E}$ & $100.25^{\circ} \mathrm{E}$ & \\
\hline Latitude & $7.0^{\circ} \mathrm{N}$ & $6.38^{\circ} \mathrm{N}$ & \\
\hline
\end{tabular}

Table 2. Frequency (\%) of urban heat island events occurring during two periods of the day as estimated from thermal contrasts observed between an urban and a rural area in three major cities in Thailand for the period 2004 to 2008 .

$\begin{array}{ccc}\text { Study area } & \text { Nighttime } & \text { Daytime } \\ & (18: 00-06: 00 \text { LST }) & (07: 00-17: 00 \mathrm{LST})\end{array}$

$\begin{array}{ccc}\text { Bangkok } & 79 & 21 \\ \text { Chiang Mai } & 68 & 32 \\ \text { Songkhla } & 75 & 25\end{array}$

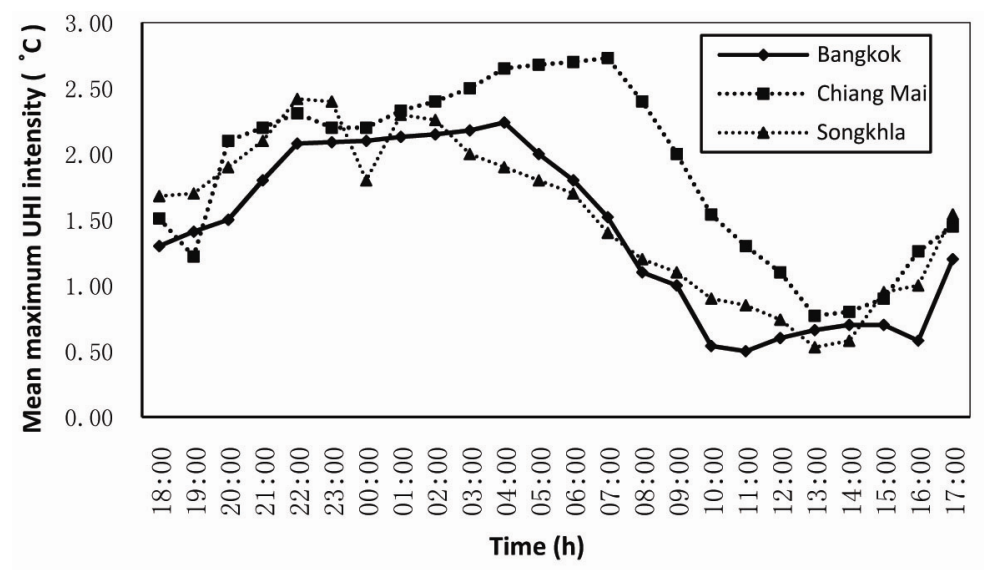

Figure 1. The hourly mean maximum UHI intensity at the study sites for the period 2004 to 2008 


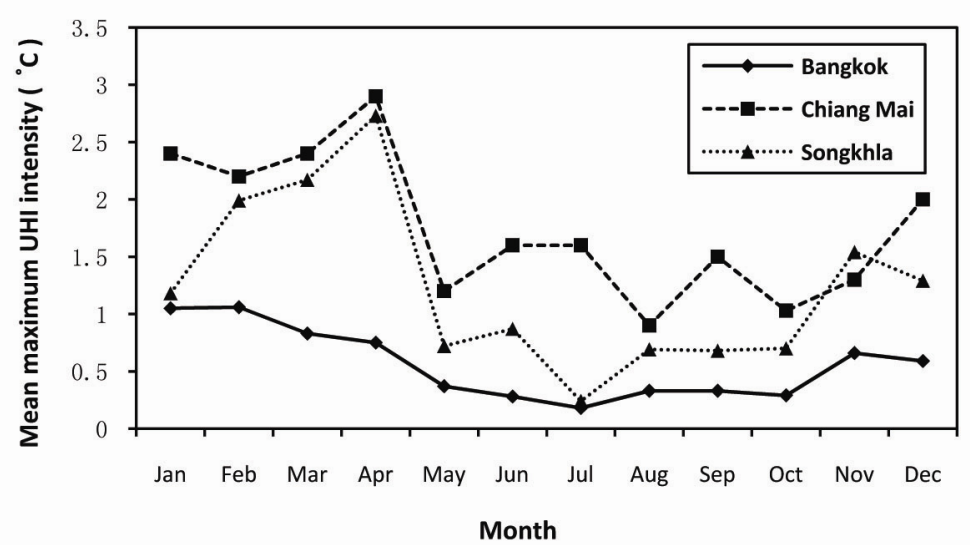

Figure 2. The monthly mean maximum UHI intensity at the study sites for the period 2004 to 2008 